\title{
Organizing for Manufacturing Innovation: The Case of Flexible Manufacturing Systems
}

\author{
Harry Boer and Koos Krabbendam \\ University of Twente, The Netherlands
}

\section{Introduction}

At the present time, an ever-growing number of new computer-aided technologies are becoming available, which are supposed to provide adopters with the opportunity to respond adequately to present competition and market pressures. However, many companies seem to have difficulties with organizing the implementation of new technology effectively. This is not surprising, considering the innovative nature of this process. Although there is a host of literature on innovation, organization and (the benefits of) new technology, the literature in which these areas are linked together is scarce. Publications addressing the manufacturing innovation process are even fewer and provide little insight into its true nature. Consequently, little is known about the effective organization of such processes. In the present article an organization model of manufacturing innovation is described, and its practicability assessed using the results of seven case studies of the implementation of flexible manufacturing systems in British, Belgian and Dutch mechanical engineering companies.

\section{Manufacturing Innovation}

This paper concentrates on the implementation of new computer-aided technologies in the operating core of industrial organizations, i.e. that part of the organization encompassing the manufacturing, maintenance, process planning, production planning, and quality control processes; the people carrying out these processes; the production resources used to make these processes feasible; and the organizational arrangements used to divide and co-ordinate the processes distinguished[1]. Manufacturing innovation[2,3] then concerns the innovation of one or more of the elements of the operating core.

Many recent technologies are new, developing combinations of different technologies, in which formerly separate items of hardware are put together and integrated with information handling capabilities, software applications and control devices $[4,5]$. These technologies offer a whole range of benefits which, together, are supposed to enable new combinations of cost-effectiveness, quality and flexibility, which were not previously feasible[6,7]. However, many organizational adaptations are required to achieve these benefits $[1,3,5,8,9,10]$. Hence, the implementation of new technology is more than the installation of

International Journal of Operations \& Production Management. VI. 12 Nos. 7/8, 1992, pp. 41-56. $\odot$ MCB University Press. 0144-3577 
IJOPM

$12,7 / 8$

42

just another piece of equipment. Rather, it entails a manufacturing innovation comprising both process and organizational innovation and resulting in levels of performance previously not feasible. In this paper we shall concentrate on the implementation of so-called Flexible Manufacturing Systems (FMSs).

\section{Flexible Manufacturing Systems} Definition

An FMS is a group of processing stations (predominantly CNC machine tools), which are interconnected by means of an automated material handling and storage system, and controlled by an integrated computer system[11].

\section{Benefits of FMS}

FMSs are designed to fill the gap between high production transfer lines and low volume standalone NC or conventional equipment. Many publications have highlighted the benefits of FMS. Table I provides a classification.

Table I.

Benefits of FMS

Technology[1]
Improved market performance

Reduced costs of operations

Improved operations management
A more adequate and rapid response to market demands for product diversity, product innovation, customer responsiveness and aggregate volume, lower sales prices, shorter delivery times, higher delivery reliability, improved product quality

Reduced direct labour or even unmanned operation, reduced indirect labour, overhead costs and floor space, shorter processing, set-up and manufacturing lead times, reduced batch sizes and work-inprogress, increased machine utilization

Linking of production control and automated manufacture, fewer human errors, increased scheduling flexibility, just-in-time manufacture, improved and consistent quality and productivity

Organizational Conditions for the Effective Operation of FMS

These benefits can be achieved only partially by implementing an FMS and using the characteristics that distinguish this technology from conventional manufacturing equipment. Specific features of FMSs are their technical flexibility (the ability quickly to change mix, routeing and sequence of operations within the parts envelope), and complexity resulting from the integration, mechanization and reprogrammable control of operations (parts machining, material handling and tool change).

The success of FMS depends at least as much on a range of organizational conditions. These conditions, which can be derived using the model proposed by Krabbendam[1], differ case by case and depend on the FMS-related goals pursued by the company involved, and the characteristics of the FMS purchased by that company. Table II provides a summary of the organizational conditions for the effective operation of FMS (see[1,5,12] for a detailed account of the 


\section{Processes}

Undisturbed, smooth manufacture

Parts, tools, programs and other inputs available and loaded when needed

Preventive maintenance of machines, other system elements, software

Detailed process planning and NC part programming

Manufacture based on realized assembly or customer orders, with the use of JIT principles

Optimal loading

Inspection of all inputs

Application of TQC concepts

\section{People}

Operators have integral knowledge of and skills in operating the FMS and solving any disturbances

Fewer operators

Maintenance engineers have knowledge of FMS technology

Maintenance engineers are committed to and adequately skilled in tracing causes of failures

People knowledgeable about and responsible for NC part program management

People knowledgeable about and responsible for tool management

Process planners have NC part programming knowledge and skills

Fewer production planners

Production planners are able to develop optimal loading procedures

People able to specify raw materials, programs and tools

Operators work according to operating procedures

\section{(Production) resources}

Diagnostic devices to trace causes of failures

Maintenance checklists

Stock of spare parts

CAPP software

Simulation software for developing optimal loading

Measuring tools for parts inspection, tool setting and assessing machine capabilities

\section{Organizational arrangements}

Multi-skilled, semi-autonomous FMS team performing all routine operating, maintenance, production planning, program change and optimization, and quality control tasks

Rules and procedures covering these activities

All-round supervisor acting as liaison with specialists

(Groups of) specialists in charge of non-routine maintenance, production planning, process planning and quality control tasks, respectively

Working groups of specialists in charge of solving problems requiring integrated solutions
Organizing for

Manufacturing Innovation

Table II.

Organizational

Conditions for the

Effective Operation of

FMS[1] 
IJOPM

$12,7 / 8$

44

way these conditions were derived). Now the question is: What are the activities that an FMS adopter has to carry out in order not only to implement an FMS but also to realize the requisite organizational conditions, and what are the possibilities for the adopter to organize this manufacturing innovation process effectively?

Organizational Conditions for the Effective Implementation of FMS In order to answer this question, we developed a model of the organization of manufacturing innovation (see Figure 1). The elements of this model can be described as follows.

\section{Constituent Activities of the Manufacturing Innovation Process}

The innovation process consists of three groups of different but inseparable activities[13]. Technological change and organizational change are quasi-cyclical problem-solving processes. Their purpose is to achieve techno-organizational solutions to the innovation problem. Each of the "cycles" comprises four stages, which concern the creation of ideas to resolve the innovation problem, the selection of the most promising idea(s), the design of the innovation, and the application of the innovation in practice. The process of internal diffusion consists of two stages: knowledge awareness and attitude formation. Internal diffusion is a continuous, ever-recurring activity feeding the technological and organizational change processes, and is based on the processing of information by and the communication between the people involved in the innovation process.

Applied to the implementation of FMS, these activities can be understood as follows. The most likely motive to start a manufacturing innovation process is a present or anticipated performance gap, which is perceived to be wide enough to induce a problem-solving process. Typically, manufacturing innovation consists of two phases during each of which technological and organizational change cycles are passed through at least once. The first phase is aimed at preparing and planning the manufacturing innovation. Once the innovation problem has been defined, initial ideas are created, aimed at filling the performance gap by implementing both technological and organizational adaptations in the organization's operating core. A typical activity during this

Figure 1.

A Model of the Organization of Innovation

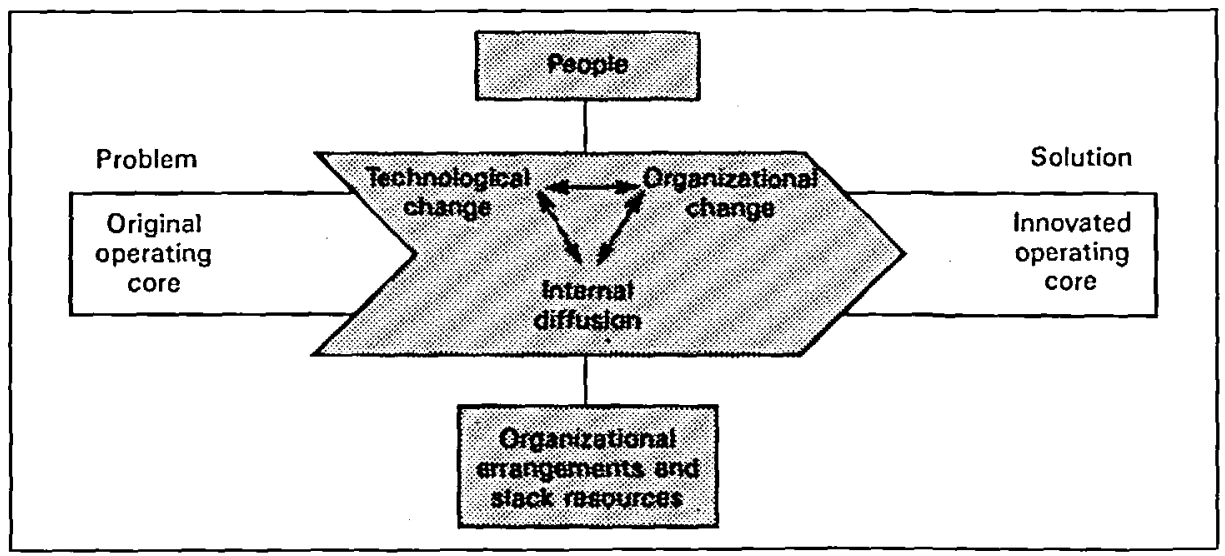


stage concerns the purposive collection of a wide range of information. Next, the most promising ideas are selected for further elaboration. Technical, financial and organizational criteria are formulated to which alternative solutions will be evaluated. Subsequently, the ideas selected are worked out into alternative operating cores, rather than alternative technical systems, which are detailed enough to put them through a thorough evaluation based on the criteria formulated in the selection stage. Finally, alternative solutions are evaluated, using multiple evaluation methods. The output of this stage includes a report on the basis of which a decision can be made regarding the adoption of FMS and the type of attendant organizational adaptations. At this point, the organization has a rough picture of its future operating core and the performance criteria attached to its functioning.

Now, the next phase can be started, which is aimed at developing and implementing the manufacturing innovation. This phase starts with the translation of the benefits pursued into technical specifications and organizational prerequisites. A lot of fairly detailed information is collected, which is required to generate alternative ideas on both the FMS and the organization of the future operating core. Next, decisions are made with respect to the exact specification of each and every element of the operating core. An installation schedule is drawn up. Vendors are asked to analyse and tender for the project and to prepare proposals, which are then evaluated in the light of the criteria formulated before. Alternative ideas on adaptations to the present operating core are selected for further elaboration. Subsequently, a supplier is selected and asked to design, develop, construct, test and install an FMS according to specifications. Simultaneously, the organizational adaptations are designed. Finally, all of these conditions are implemented. People are trained, new procedures instilled, and an FMS group is formed. The FMS is assembled, tested, and accepted on the basis of satisficing results of pilot production, shipped, installed and put into operation. At the end of this stage, most of the operating core's output will be produced by the FMS. The operating core itself is characterized by the conditions required for the effective operation of the FMS.

As to the internal diffusion process, knowledge awareness and attitude formation are crucial events which stimulate technological and organizational change. Initially, the innovation process will never unfold unless a performance gap, wide enough to demand corrective action, is perceived or anticipated. Furthermore, FMS will not be taken into consideration if the company is not aware of the existence of this technology. Then, the people involved in the innovation process must have a favourable attitude towards FMS, or else it will not even be considered. And finally, organizational measures will not be taken unless their necessity is recognized and accepted. The quality of these activities depends to a considerable degree on the extent to which the organization has effectively organized the underlying processes, namely communication and information processing. In this respect, the characteristics of the innovation process play an important role.
Organizing for Manufacturing Innovation 
IJOPM

$12,7 / 8$

46
Characteristics of the Innovation Process

The previous description of the manufacturing innovation process illustrates the wide diversity of activities to be performed in order to innovate a company's operating core. The interdependence of these activities is fairly high: decisions on the benefits pursued, the characteristics of the technology and the organizational characteristics, all these factors are mutually dependent. Furthermore, the organization is not likely to produce a new operating core without interruptions, setbacks and surprises: goals will be redefined, formerly accepted solutions will be rejected and exchanged for alternative solutions, and, as a result, project schedule and budget overruns will occur. In other words, manufacturing innovation involves a certain amount of uncertainty. Finally, the process is characterized by a certain degree of complexity: FMSs are a complex combination of a wide variety of technologies, and the organizational prerequisites of FMS are difficult to assess accurately prior to implementation.

The effectiveness of the innovation process mainly depends on the extent to which the people involved in the process as occupants of one or more innovation roles, and the organizational arrangements regulating their collaboration, fit these characteristics.

\section{Innovation Roles}

In several publications[e.g. 13,15,16] a range of innovation roles have been described. Each of these roles represents a combination of cognitive, behavioural and positional attributes[14]. A distinction can be made between operational roles, and managing and supporting roles (see Table III).

The operational roles are based on the types of knowledge and skills required to cope with the complexity and diversity of the constituent activities of the innovation process. Two different roles are needed to collect information. The function of the gatekeeper is to keep the organization abreast of current developments by gathering general information on suppliers, markets and technologies. The role of the scout concerns the collection of specified data needed to perform problem-solving activities. The roles of the idea generator, and the technological and organizational problem solvers are needed to transform available information into ideas and solutions to the innovation problem. Considering the nature of manufacturing innovation, it is difficult to distinguish between the technological and the organizational problem solver, other than by the aspects they are covering. The difference between the idea generator and problem solvers is only slightly clearer.

Considering that the implementation of FMS is a major part of the manufacturing innovation, process planners are to play a key role in the innovation process. The complexity of FMS technology requires, in addition, that experts in the fields of maintenance, production planning and quality control are involved too. All operating core functions, including the manufacturing function, should be involved in the identification, design and implementation of the organizational adaptations required, in particular as their own functions are concerned. Furthermore, certain stages of the innovation process may require the 
involvement of higher levels of management. Obviously, their job involves making key decisions, such as deciding whether or not to adopt FMS, and setting goals and constraints to the innovation. However, more important may be their role in carrying through fundamental adaptations to the operating core, such as the Innovation introduction of a multi-skilled, semi-autonomous FMS team, and the establishment of cross-functional working groups of specialists.

\section{Operational roles}

\section{Gatekeeper Collects and channels information about important changes in the internal and external environments}

Scout Surveys a specified, yet unexplored field by collecting specific information

Idea generator

Technological problem solver

Organizational problem solver
Analyzes or synthesizes information about markets, technologies, approaches, or procedures, from which are generated ideas for solving the innovation problem

Solves the technological aspects of the innovation problem

Solves the organizational aspects of the innovation problem

\section{Managing and supporting roles}

Champion

Project leader/ organizer

\section{Integrator}

Coach

Ambassador

Problem owner
Recognizes, proposes, pushes and demonstrates a new idea for formal management approval, using his position and enthusiasm

A (possibly) high-ranking person who initiates and realizes the organization of the manufacturing innovation process, and subsequently plans and co-ordinates the diverse sets of activities and people; involved in moving an idea into practice; focused on decision making, interested in a broad range of disciplines.

Balances attention between different innovation problems (if different innovation problems are being solved simultaneously); authority possibly based on fairly high formal position.

Guides and develops less experienced personnel in their critical roles; through his tenure and position is able to support and protect the innovation process

An approachable and personable communicator who disseminates the innovation within the organization, by communicating the state of the innovation process from the problem solver(s) to other people in the organization

Perceives a performance gap (i.e. a difference between the actual situation and that desired) which is sufficiently wide to start corrective actions; a crucial role but difficult to implement consciously
Table III. Innovation Roles 
IJOPM

$12,7 / 8$
In addition, the innovation process must be staffed with people managing and supporting the innovation process by co-ordinating the wide diversity of interdependent activities performed, creating conditions conducive to communication, establishing suitable co-ordination mechanisms, and providing leadership. The people fulfilling these roles are selected primarily on the basis of their positions and behavioural attributes, rather than their expertise in one or two fields. (See Table III for more details.)

\section{Organizational Arrangements and Slack Resources}

The implementation of the innovation roles, though a necessary condition, is not sufficient to cover all of the diversity and complexity, let alone the interdependence and uncertainty involved in manufacturing innovation. In this section we shall describe additional requirements with regard to the collaboration between the role occupants.

Basically, two strategies may be applied to increase the ability to cope with the uncertainty involved in the innovation process[17] One strategy is to increase the information processing capacity, by establishing lateral linkages between functional departments. The other strategy is to reduce the amount of information to be processed, by extending completion dates (time slack) or raising budgets (financial slack), rather than lowering aspiration levels (quality slack) [18].

The complexity of the manufacturing innovation process requires a wide range of knowledge bases and skills. However, the organization may not have all of the expertise required readily available. The most effective strategy to prevent knowledge gaps is to train and educate organizational members in a wide range of fields, including technical and organizational issues, leadership, motivation and communication. A second strategy is to allow for trial-and-error learning about the innovation goals, process and organization. Then, the innovation process is more likely to produce a qualitatively sufficient output, albeit at the cost of time incurred in learning.

The most obvious way to handle the diversity dimension is the implementation of the innovation roles described before. The interdependence dimension can be covered best by creating lateral linkages between role occupants. However, their number may easily become too large, creating difficulties for co-ordinating their contributions. A promising strategy to overcome these contradictory demands is the creation of small groups of idea generators, technological and organizational problem solvers, and scouts, solving specialist problems such as writing and testing $\mathrm{NC}$ part programs, designing quality assurance procedures or purchasing peripheral equipment. These functional groups can be established at the time required and disbanded after they have served their purpose. A core group, staffed by the persons fulfiling the project leader/organizer, integrator, ambassador, and coach roles, acts as project manager, planning, organizing and co-ordinating the process, and enhancing communication between the functional groups.

In Table IV the type of activities to be performed, and the type of conditions to be established in order to increase the likelihood that the manufacturing 


\section{Process}

Technological and organizational change, involving the creation, selection, development and implementation of ideas and (potential) techno-organizational solutions to the innovation problem

Internal diffusion, involving bringing about an awareness of and an attitude towards ideas and (potential) solutions

Balanced attention to, and integration of results of, these activities, including the establishment of mutually adjusted technical and organizational goals, the design and implementation of a techno-organizational solution to the innovation problem, communication between the people involved in the innovation process, and diffusion of information to people who will be involved in the future or whose functioning will be affected by the manufacturing innovation

\section{People}

The implementation of the roles of idea generator, technological problem solver, organizational problem solver, gatekeeper and scout

Selection of people to perform these roles, predominantly on the basis of their knowledge and skills in the fields of manufacturing, maintenance, process planning, production planning and quality control

The implementation of the roles of champion, project leader/organizer, integrator, coach, ambassador and problem owner

Selection of people performing these roles, predominantly on the basis of their position and behavioural attributes

Involvement of the workforce, as a source of operational knowledge and as future users of the innovation

Involvement of higher management, as organizer of the innovation process (getting separate functions to solve the innovation problem jointly), and as organizational problem solver (in particular as the implementation of more radical and integrated adaptations to the operating core is concerned)

\section{Organizational arrangements and slack resources}

Extensive use of lateral linkages to enhance communication between, and to increase learning by, different specialist functions

The creation of slack resources, especially as regards time and budgets, both prior to and after installation

The establishment of temporary functional groups, comprising the idea generator, technological and organizational problem solver, and scout roles, to resolve specialist problems

The establishment of a core group (for the duration of the process), comprising the project leader, integrator, ambassador, and coach, to plan, organize and co-ordinate the process, and to enhance communication between the functional groups, and with other parties
Organizing for Manufacturing Innovation

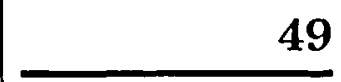

Table IV.

Summary of Innovative Activities and Conditions Conducive to these Activities 
IJOPM

$12,7 / 8$

50

innovation process will lead to the effective operating core pursued, are summarized. If the organization is not aware of the necessity to create these conditions, or not prepared to implement them, the goals set will only be partially achieved, and that later than expected.

\section{Research Design}

The remainder of this paper is aimed at assessing the extent to which the conditions contribute to the effective conduct of the innovation process by which a company's operating core is transformed to comprise an effectively operated FMS. In order to provide an answer to this question, we conducted a number of longitudinal case studies into the implementation and early operation of flexible manufacturing systems by four British, one Belgian and two Dutch mechanical engineering companies. We shall not dwell on all the results but concentrate on the question formulated above.

\section{Observations}

Goal Achievement

At the end of the longitudinal case studies, most companies reported that they had failed to meet the financial criteria set to the innovation. In all cases but one, the project had lasted longer than anticipated. Most companies achieved a number of market advantages, such as improved product quality and shorter delivery times for existing variants, and operational advantages, such as reduced direct labour, shorter set-up times, reduced work-in-progress and reduced scrap and rework. The organizational measures taken by them, together with the conditions that had already been implemented prior to the decision to adopt FMS on the one hand, and the characteristics of this technology on the other, mainly account for this (see left-hand side of Figure 2). However, none of the companies was entirely successful.

\section{Barriers to Goal Achievement}

Barriers to goal achievement (see right-hand side of Figure 2) seem to fall into three broad categories. First, the extent to which the companies achieved the FMS-related goals was largely determined by organizational bottlenecks originating from the fact that they had failed to create all of the organizational prerequisites by the time the system was implemented. In many instances this caused the delay of otherwise achievable benefits. Furthermore, in some cases insufficient preparation negatively affected the companies' ability to cope with certain technical problems and unexpected changes in the marketplace, which had clear consequences for the success of the manufacturing innovation.

As one company stated, "teething troubles are normal during commissioning". However, most companies encountered many more technical problems than they had expected. The companies involved were relatively early adopters of FMS. They were, therefore, among the first to deal with all kinds of problems related to the specification and the use of an immature technology comprising customized, one-off elements. All companies found it difficult to draw up detailed specifications of a system that would meet their purposes. Several projects were 
delayed due to the FMS supplier finding it difficult to produce an FMS that met the customer's requirements. Engineering faults in, and problems with communication between and standardization and integration of, both hardware and software elements of the system were frequently mentioned as major problems, even in the more or less established elements of FMS technology. Several suppliers lacked experience with either computer applications or machining tools, which, together with the complexity of FMS, contributed to problems of this nature. Furthermore, some suppliers had decided to subcontract part of the project, but appeared to lack the capabilities to manage the project. Generally, the development of the one-offs took considerably more time than anticipated. In some cases, severe design and construction faults may well be permanent obstacles to the intentions of the companies involved. In one case, part of the system needed full-time attention, meaning that the anticipated reduction of direct labour could be achieved only partially. Due to a design fault, set-up times of another company's FMS were much higher than specified, which accounted for a longer cycle time and, consequently, a lower machining capacity than foreseen. Together with a higher market demand than anticipated, this forced the company to operate part of its old equipment. As a result the company had to accept higher lead times and work-in-progress than expected. Due to still unresolved software problems, the availability of a third company's system was lower than anticipated. Pending the solution of similar problems, a fourth company had postponed the implementation of organizational adaptations aimed at reducing lead times and work-in-progress, needed to eventually achieve justin-time manufacture to assembly orders.

Several companies were faced with considerable changes in the marketplace occurring during the manufacturing innovation process, and found it difficult to handle these changes adequately. In two cases the market collapsed during the innovation process. By the end of the case study, one company was programming alternative products. The other company had not found alternative products, causing it to operate its FMS for one shift only, instead of the anticipated three shifts. Finding new products will remain a problem as this FMS was designed for a relatively narrow envelope of components, and flexible manufacture of parts outside this envelope would require a virtually new FMS. Two other companies encountered a much higher demand than forecast, causing capacity constraint problems. Technical problems together with the unexpectedly high market demand forced both companies to operate much more of their old production line than anticipated, even though this increased lead times and workin-progress, due to problems of integration between the existing facilities and the FMS.

At the end of the case studies, the companies had realized many of the conditions required for the effective operation of FMS. However, they also encountered a number of organizational barriers which will be discussed here together with their impact on goal achievement. Generally, the process planning function was the one best prepared to meet the requirements of FMS. The process planners were trained properly to make detailed process plans and accurate NC part programs. All companies had already made progress in totally 
IJOPM

$12,7 / 8$ controlling the quality of their products, or accelerated their efforts in this field prior to or shortly after the implementation of the system. Yet, most of the companies needed more time than anticipated to ensure the quality of their products and operations, due to the technical problems discussed before, or problems related to the insufficient quality of raw material. Taken altogether, the organizational measures aimed at preparing the production planning function to properly plan and schedule the FMS have been sufficient, in all the companies. Yet, several companies failed to achieve one or two of their logistics-related goals by the time set, due to the technical problems, market-related factors and problems of integration with existing facilities indicated before.

More serious barriers appeared to be the following. Most of the companies had not succeeded in sufficiently preparing their manufacturing and maintenance functions to operate, maintain and regulate the FMS effectively. Some companies started to introduce preventive maintenance just prior to or shortly after the installation of the system. All companies' maintenance engineers had received insufficient training prior to the installation of the system and they had to acquire most knowledge and skills by assisting during the installation of the system and by resolving teething troubles. However, due to the pressure to get the system into operation, in many companies learning about the system was restricted to firefighting operational problems, rather than instilling a commitment to trace the causes of failures and developing the relevant skills. Several companies had not purchased diagnostic devices, and lack of proper equipment reinforced this attitude. All the companies had maintenance checklists to be delivered together with the FMS, which, however, appeared to need considerable adjustment.

Due to maintenance and quality problems, together with technical problems and changes in the marketplace, several companies had not achieved a smooth, undisturbed manufacturing process. Furthermore, many FMS operators needed additional training to obtain integral knowledge and skills in operating the system and coping with disturbances, in spite of the training given to them prior to the installation of the system. In all companies, the process planners had to spend a great deal of their time troubleshooting.

Most of the companies had paid limited attention to establishing rules and procedures covering the tasks and responsibilities of the shopfloor. Two companies had basically implemented a semi-autonomous FMS team of multiskilled operators performing all routine tasks. Other companies had made a similar arrangement, but found it difficult to get the group functioning up to expectations, due to the operators still being insufficiently skilled, as mentioned before. In some companies the FMS supervisor acted as liaison with specialists or specialist groups. In other companies the process planner responsible for the system was informally assuming this role.

So, most companies underestimated the necessity to implement the required organizational adaptations. After installation of the FMS, they gradually became aware of the necessity to implement more adaptations than just the usual ones in relation to the installation of new equipment. However, all companies tended to stick to current practices rather than to implement organizational arrangements such as a multi-skilled FMS team to perform routine tasks, and cross-functional 
teams of specialists to perform non-routine activities. Consequently, several companies found it difficult, not only to cope with the technical problems and market-related problems encountered, but also to create the organizational conditions they had failed to implement prior to the installation of the system. And still some adaptations, in particular the more radical ones, have never been appreciated by some of the companies.

\section{Explanation}

Actually, none of the companies perceived the implementation of FMS as a manufacturing innovation process. This perception accounts for a complex of symptoms which, together, explain the level of success obtained by the companies. The main symptoms are related to the innovation roles implemented to perform the manufacturing innovation process; the organizational arrangements implemented to regulate the co-operation between role occupants, and the slack resources created for the purpose of the innovation process. These issues had obvious consequences for the activities performed to resolve the innovation problem.

The companies' perception led them to adopt a one-sided, technical approach to resolving the innovation problem. FMS technology was considered the panacea for the company's problem, in each case. However, the majority of the companies underestimated the diversity of the activities to be performed in order to get the system operating effectively. Consequently, they did not or could not appreciate the interdependence of these activities and decided to have their process planners handle the innovation. Fulfilling the roles of problem owner, idea generator, technological and organizational problem solver, project leader, gatekeeper, scout, and champion, the process planning function was involved in all the major decisions which were made. The other operating core functions were either not involved or to a very limited extent. In all the companies the manufacturing department had a say as far as the selection of and the training programme given to the future FMS operators were concerned.

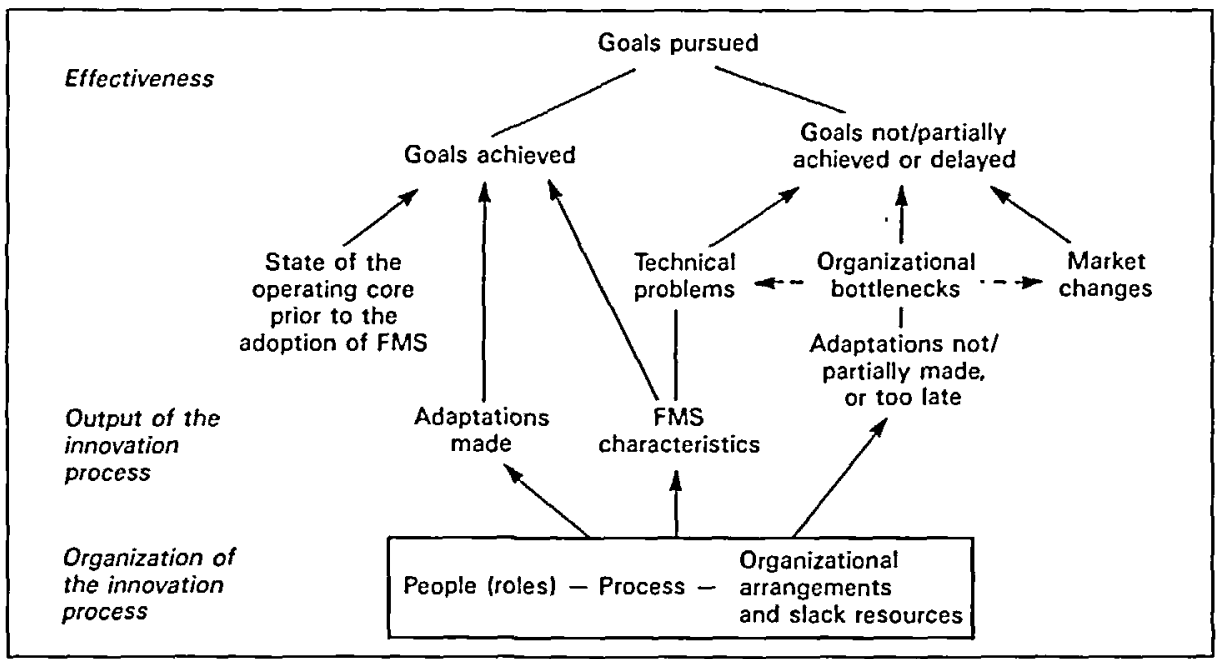

Organizing for Manufacturing Innovation

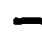


IJOPM

$12,7 / 8$
The production planning department played no significant role in half of the cases. Usually, the maintenance function was involved to the extent that they were requested to assist with the preparation of the FMS site and the installation of the system. In three cases only, the quality control department was involved prior to installation. In some cases, the general director and/or the technical director were frequently involved in the project, in one case even leading the project. In the other companies, the role of higher management was largely restricted to approving the investment proposal.

The companies paid insufficient attention to implementing the other roles, in particular the ambassador. Most information was exchanged using formal channels of communication. Also, all companies established a project team for the duration of the process, and in several cases temporary groups were active in handling specific problems. However, dominated by the process planning function occupying the innovation roles to the extent discussed before, these teams were a mixture of the functional and core groups we had expected. Consequently, the main purpose of the internal diffusion process, i.e. increasing the information processing capacity needed to handle the uncertainty and complexity involved in innovation, could not be achieved. Issues falling outside the scope of the process planners, could not be recognized or handled adequately prior to the installation of the system.

Considering all this, the process planners actually performed an excellent job. Not only did they specify the FMS, they also designed many of the required organizational adaptations. At the same time, however, they were insufficiently skilled to recognize and handle all of the diversity and interdependence of the activities that should have been performed in order to prepare the operating core appropriately. Failing to understand that the technical characteristics of FMS would contribute only partially to the realization of the market and operational benefits pursued, they put insufficient effort into translating these benefits into an integrated techno-organizational solution to the innovation problem: none of the companies added other than the most obvious organizational specifications to the technical ones, and they did so only after the decision had been made to adopt FMS. Only after installation of the system, with technical problems abundant and operational experience increasing, did the companies start the implementation of additional conditions. Some companies decided to establish temporal linkages among the departments affected by the FMS. The other companies kept relying on their existing structure which, however, was not very suitable for handling the wide diversity of problems encountered. Consequently, the additional organizational conditions were the result of trialand-error learning by separate functions, rather than the concerted effort of the operating core functions. As a result, most companies had to spend more time and effort than was strictly needed to achieve the innovation pursued. However, none of the companies had built much time or financial slack into their project. On the contrary, all the companies had attached short-term financial criteria to the investment and put the project under time pressure. In most cases, time pressure was further increased due to the supplier failing to deliver the system at the negotiated time. This situation reinforced the companies' 
tendency to firefight problems rather than to take time to resolve them once and for all.

As a result, none of the companies achieved all of the FMS benefits pursued at the required time. Consequently, financial goals were automatically reduced.

Organizing for Manufacturing Innovation

\section{Conclusion}

The analysis of seven cases of the implementation of FMS showed that the companies involved achieved many but not all of the FMS-related goals pursued. Each company created several but not all of the conditions which, according to our model, would enhance the likelihood of the company producing the intended manufacturing innovation. The companies' perception of the innovation problem led them to adopt a one-sided, technical approach to resolving the problem. Many of the innovation roles were not fulfilled, and several occupants of those roles fulfilled were insufficiently skilled to perform the roles properly. Most internal diffusion remained within the core groups of process planners performing, supporting and managing the innovation process. More use should have been made of organizational arrangements such as liaison roles and lateral linkages, in order to increase the communication between a wider range of functions, in particular during the initial stages of the innovation process, when the key decisions were made. Finally, most companies had built insufficient slack into their project.

These observations explain why the companies, initially, aimed at a technical, rather than an integrated and balanced techno-organizational solution. After installation, it appeared that more adaptations should have been made. Due to the companies' existing structure and insufficient slack, many of these adaptations were the result of poorly organized, protracted and unforeseen trialand-error learning processes. Consequently, time-related and financial goals were automatically reduced, in most cases.

The research seems to confirm that the organization model of manufacturing innovation is a practicable tool for deriving the conditions enhancing the likelihood of new technology adopters to achieve their purposes at the time set. Only then, will organizational adaptations be given due consideration. Technical problems will be prevented or resolved more rapidly. Changes in the marketplace will be anticipated or dealt with more adequately. Less time will be lost for trial-and-error learning about the innovation. In effect, the manufacturing innovation process will evolve more rapidly and successfully.

\section{References}

1. Krabbendam, J.J., Nieulve technologieèn en organisatorische maatregelen, University of Twente, School of Management Studies, Enschede, 1988.

2. Braun, E., "Constellations for Manufacturing Innovation", Omera, Vol. 9 No. 2, 1981, pp. 247-53.

3. Bessant, J. and Grunt, M., Management and Manufacturing Innovation in the United Kingdom and West Germany, Gower, Aldershot, 1986.

4. Buchanan, D.A. and Boddy, D., Organizations in the Computer Age, Gower, Aldershot, 1983. 
IJOPM

$12,7 / 8$

56

5. Boer, H., Hill, M.R. and Krabbendam, JJ., "FMS Implementation Management: Promise and Performance", Intemational Joumal of Operations \& Production Management, Vol. 10 No. 1,1990 , pp. 5-20.

6. Goldhar, J.D. and Jelinek, M., "Plan for Economies of Scope", Hanard Business Retiew, Vol. 61, November/December 1983, pp. 141-8.

7. Meredith, J.R., "The Strategic Advantages of the Factory of the Future", California Management Reriew, Vol. 29 No. 2, 1987, pp. 27-41.

8. Senker, P.J., “Implications of CAD/CAM for Management”, Omega, Vol. 12 No. 3, 1984, pp. 225-31.

9. Willenborg, J.A.M. and Krabbendam, J.J., "Industrial Automation Requires Organizational Adaptations", Intemational Joumal of Production Research, Vol. 25 No. 11, 1987, pp. 1683-91.

10. Gerwin, D., "A Theory of Innovation Processes for Computer-aided Manufacturing Technology", IEEE Transactions on Engineering Management, Vol. 35 No. 2, 1988, pp. 90-100.

11. Groover, M.P., Automation, Production Systems, and Computer-integrated Manufacturing, Prentice-Hall, Englewood Cliffs, NJ, 1987.

12. Krabbendam, J.J. and Boer, H., "Anticipating and Managing Organizational Measures for the Implementation of New Technologies: The Case of FMS, Proceedings of the 2nd International Production Management Conference on Management and New Production Systems, Fontainebleau, France, 13-14 March 1989.

13. During, E.W., Innovatieproblematiek in kleine industriële bedrijten, Van Gorcum, Assen, 1986.

14. Boer, H., Organising Innovative Manufactuning Systems, Gower, Aldershot, 1991.

15. Frohman, A.L., "The Performance of Innovation: Managerial Roles", Califormia Management Review, Vol. 20 No. 3, 1978, pp. 5-12.

16. Roberts, E.B. and Fusfeld, A.R., "Staffing the Innovative Technology-based Organization", Sloan Management Review, Spring 1981, pp. 19-34.

17. Galbraith, J.J., Designing Complex Organisations, Addison-Wesley, Reading MA, 1973.

18. Quinn, J.B., “Managing Innovation: Controlled Chaos", Harrard Business Review, Vol. 63, May-June 1985, pp. 73-84. 


\section{This article has been cited by:}

1. Chiara Demartini, Piero Mella. 2011. Time Competition. The New Strategic Frontier. iBusiness 03:02, 136-146. [CrossRef]

2. Jenny Y. Xin, Andy C. L. Yeung, T. C. E. Cheng. 2008. Radical innovations in new product development and their financial performance implications: An event study of US manufacturing firms. Operations Management Research 1:2, 119-128. [CrossRef]

3. Ozden Bayazit. 2005. Use of AHP in decision-making for flexible manufacturing systems. Journal of Manufacturing Technology Management 16:7, 808-819. [Abstract] [Full Text] [PDF]

4. . The Need for a New Approach 159-174. [Citation] [Full Text] [PDF] [PDF]

5. Shahid Yamin, Felix Mavondo, A Gunasekaran, James C. Sarros. 1997. A study of competitive strategy, organisational innovation and organisational performance among Australian manufacturing companies. International Journal of Production Economics 52:1-2, 161-172. [CrossRef]

6. Injazz J. Chen, Chia-Shin Chung, Atul Gupta. 1994. The Integration of JIT and FMS:. Integrated Manufacturing Systems 5:1, 4-13. [Abstract] [Full Text] [PDF] 